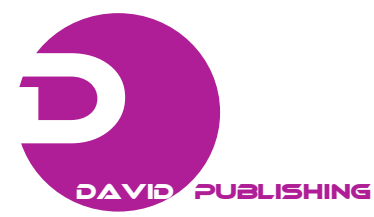

\title{
Effects of Flicker in a Distribution Grid with High PV Penetration
}

\author{
Andreas Spring ${ }^{1}$, Georg Wirth ${ }^{1}$, Gerd Becker ${ }^{1}$, Robert Pardatscher ${ }^{2}$ and Rolf Witzmann ${ }^{2}$ \\ 1. Department of Electrical Engineering, University of Applied Sciences Munich, Munich 80335, Germany \\ 2. Department of Electrical Engineering and Information Technology, Technische Universität München, Munich 80333, Germany
}

Received: July 09, 2014 / Accepted: September 16, 2014 / Published: December 31, 2014.

\begin{abstract}
The quantity of installed PV (photovoltaic) systems in the German distribution grid is still increasing. In some areas, the installed PV capacity exceeds $5 \mathrm{~kW}$ per HC (house connection). Therefore, the load flow changes its characteristics and leads to new requirements for the grid. In some areas, the power feedback is higher than the delivery and the installed PV capacity becomes the decisive factor for grid planning. This paper discusses the impact of PV systems on the flicker level. The focus hereby is on the correlation among the flicker level, the grid voltage and the meteorological parameters. Different approaches to investigate if there is an influence of PV systems on the maximum flicker are taken into account. Furthermore, an investigation if the normative limit is exceeded will be shown.
\end{abstract}

Key words: Grid integration, stability, PV.

\section{Introduction}

The generated power of PV (photovoltaic) systems represents a growing part of the electrical energy supply in Germany. In some areas, more than $5 \mathrm{~kW}$ per HC (house connection) are installed [1]. This leads to new challenges to ensure the required power quality. One power quality criterion is the flicker level.

Flicker is a subjective impression of the discontinuity of visual perception caused by a variation of voltage, and therefore, a volatile luminance. The flicker can be measured by a flickermeter (defined in Ref. [2]) that based on a reproduction of a $60 \mathrm{~W}$ incandescent lamp, the sensitivity of the human eye and the corresponding brain reaction. For the evaluation of the emissions, different flicker limit curves have been determined. The reasons for flickers are voltage fluctuations, thereby, the curve form of this variability (sinusoidal, ramp, rectangle) and the frequency are essential.

Corresponding author: Andreas Spring, M.Sc, research fields: impact of PV systems on the flicker and reactive power flow caused by PV inverters. E-mail: andreas.spring@hm.edu.
Flickers can be characterized by Ref. [3]:

- short-term flicker (index st (short term)) in a time period of 10-min and long-term flicker (index lt (long term)) in a time period of two hours;

- the relative voltage changes $\Delta u(t)$;

- different correction factors.

$P_{l t}$ (long-term flicker) is one relevant parameter for the power quality. The permissible value of $P_{l t}$ in a low voltage grid even at the weakest grid node, produced from the totality of all feeders, according to the German low voltage guide line [4]:

$$
P_{l t} \leq 0.5
$$

The value is calculated from 12 consecutive $P_{s t}$ (short-term flicker) [5]. Flicker values are given dimensionless:

$$
P_{l t}=\sqrt[3]{\frac{\sum_{i=1}^{12} P_{s t, i}^{3}}{12}}
$$

The limiting value for the short-term flicker is:

$$
P_{s t} \leq 1.0
$$

This value is decisive for product standardization but not for power quality. Nevertheless, due to the temporal resolution, this $P_{s t}$ is used in the following to 
analyse the dependency of the flicker on the PV feed-in. The $P_{l t}$ is only used to analyse exceedances of the normative limit.

Higher values leads to disturbing perceptions caused by voltage fluctuations and variations in the luminance by more than $50 \%$ of the test persons. Eq. (4), according to Ref. [5], describes the calculation instruction. Essential is the voltage variation $\frac{\Delta U_{\max }}{U}$ in percentage, $R$ and $F$ are frequency and form factors, $r$ is the repetition rate per minute.

$$
P_{s t}=0.365 \cdot R \cdot F \cdot\left(\frac{r}{\min ^{-1}}\right)^{0.31} \cdot\left|\left(\frac{\Delta U_{\max }}{U}\right) / \%\right|
$$

Frequency and form factors for various repetition rates and relative voltages changes are given in Ref. [5]. The size of these factors is in the range of 0.2-1.4.

On days with a fluctuating cloudiness, the ramp rate of the irradiation, and thereby, the irradiation changes are very high. The generated output power of PV systems is strongly volatile [6]. This has an intense effect on the grid voltage and thereby, possibly on the flicker. In this paper, the evaluation of the short- and long-term flickers depending on the relative grid voltage, the time of the day, date of the year, global irradiation gradients and the clear sky index in an area with a high PV penetration is shown.

\section{Database}

To gain more knowledge of the changing grid requirements, the Bayernwerk $A G$ initiated the project "Grid of the Future" (Netz der Zukunft) [7] in cooperation with the University of Applied Sciences Munich and the Technische Universität München. In this project, a medium voltage grid in Lower Bavaria and the underlying LV (low voltage) grids are analysed. This area stands for high PV yields (for Germany) and an above average PV penetration ( $5 \mathrm{~kW} / \mathrm{HC})$. Around 560 smart meters are installed, mainly at house connections with PV systems. A database collects the ten-min average data from the measurement devices. The $P_{s t}$ is one electrical parameter that is recorded. All results refer to the period from January 2011 to December 2012. Thus, the test series include two complete summers.

To get significant results, several evaluation steps are necessary. The low voltage grids have to be analysed separately because of the high data volume. Each smart meter calculates the ten-min average $P_{s t}$ value for all three phases of the electricity grid. This leads to 432 values per smart meter and day, and therefore, to nearly five million data values per year for a grid with 30 smart meters.

All flicker values are real measurement data. Therefore, it is not possible to match these values bijective to PV systems or loads. Different approaches to allocate the flicker levels to loads or PV systems are realised. The assignment is done for the relative grid voltage, the date and time as well as the global irradiation gradients and the clear sky index.

The clear sky index is the quotient of the measured irradiation $G_{\text {measured }}$ to the clear sky reference irradiance $G_{\text {clear sky }}$ on the particular location and day [8] (see Eq. (5)). The clear sky index from one irradiation sensor in the investigation area is calculated and used for this study. A clear sky index value equal to one describes clear sky conditions. Days with a fluctuating cloudiness cause clear sky index values different to one. Cloud shadowing cause clear sky index values lower than one, irradiance enhancements cause clear sky index values higher than one.

$$
k_{T}=\frac{G_{\text {measured }}}{G_{\text {clear sky }}}
$$

The investigation of the flicker is made for several low voltage grids. The results, however, are similar for all investigated grids. Therefore, the detailed results for only one low voltage grid in the year 2012 will be discussed and shown in the following evaluations of the $P_{s t}$. The evaluation of the $P_{l t}$ is done for several low voltage grids.

The used LV grid for $P_{s t}$ analysis can be characterized by a high PV penetration of more than $1,050 \mathrm{~kW}$ of installed power in June, 2012. Thirteen of 
144 house connections are equipped with smart meters. This leads to a PV penetration of $7.3 \mathrm{~kW} / \mathrm{HC}$.

\section{Results}

\subsection{Distribution of the Long-Term Flicker}

Fig. 1 shows the highest $10 \%$ of the measured long-term flicker in the investigation area. The flicker are separated in the years 2011 (Fig. 1a) and 2012 (Fig. $1 b)$ in descending order. In all LV grids emerge flicker higher than the normative value for PV systems of Ref. [4] of 0.5. Statements whether a feed-in or load is responsible for the flicker higher than 0.5 are not possible. To make the exceedances of Ref. [4] more obvious, only the $10 \%$ highest flicker values are displayed.

The small village Thundorf reveals the highest exceedances of all LV grids for both years. In 2011, $3.5 \%$ of all flickers are higher than the normative value; in $2012,1.11 \%$. With the exception of Moos are the long-term flickers in 2012 lower than that in 2011 and less exceedances of the normative value occur. Due to the fact that there are no relevant changes in the consumer loads in the both years, but a built-up of new PV systems the reduction can be attributed to grid enforcement measures. Additionally, the $98 \%$ and $95 \%$ quantile is visualized in Fig. 1 (red dots). The exact values of the quantile are summarized in Table 1 for the year 2011.

\subsection{Correlation of the Short-Term Flicker with the Relative Grid Voltage}

As shown in Section 3.1, there are exceedances of the power quality criterion long-term flicker. Consequently, there is a need to analyze the perpetrator of the exceedances.

All following results refer to the measured short-term flickers, because of the higher temporal resolution compared to the long-term flicker. The short-term flicker is not relevant for power quality. It is only significant for product standardization. The evaluation of the dependency of the flicker on PV systems contains

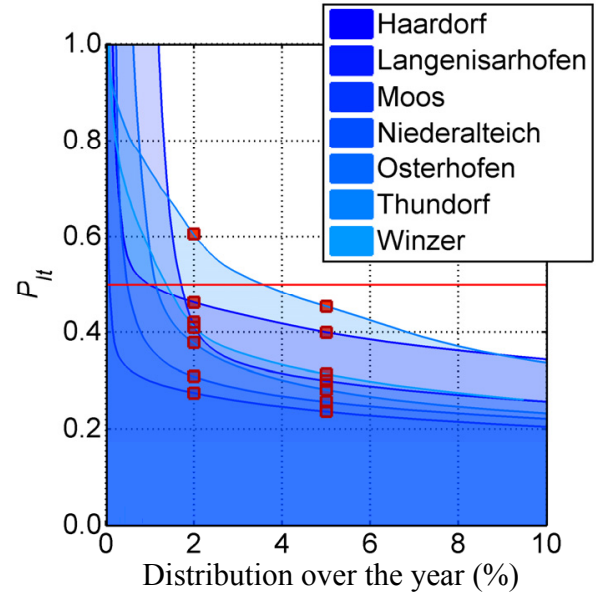

(a)

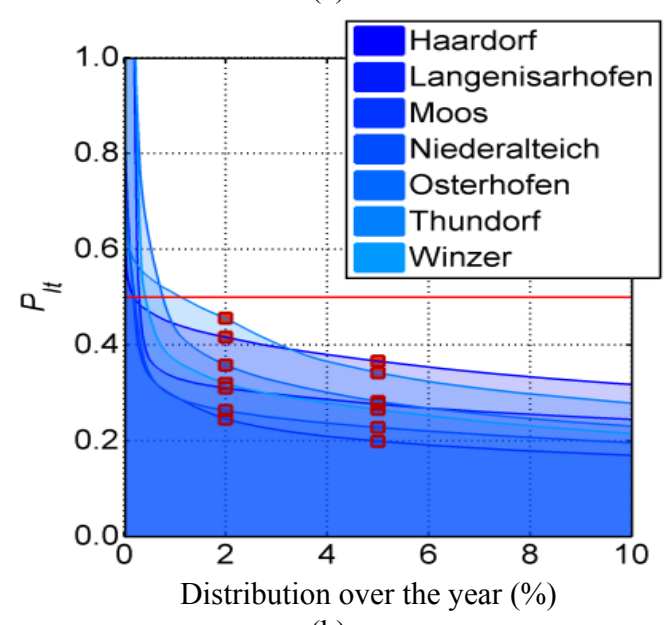

(b)

Fig. 1 Long-term flicker in the seven investigated low voltage grids: (a) in the year 2011; and (b) in 2012.

Table 1 Flicker level of the highest $2 \%$ and $5 \%$ of all values and the exceedances of the normative value of Ref. [4] in 2011.

\begin{tabular}{llll}
\hline Village & 2011 & & \\
\hline Plt & $>0.5$ & Max. 5\% & Max. 2\% \\
Haardorf & $0.98 \%$ & 0.24 & 0.27 \\
Langenisarhofen & $1.75 \%$ & 0.26 & 0.31 \\
Moos & $0.09 \%$ & 0.28 & 0.38 \\
Niederalteich & $0.50 \%$ & 0.30 & 0.41 \\
Osterhofen & $1.16 \%$ & 0.31 & 0.42 \\
Thundorf & $3.55 \%$ & 0.45 & 0.61 \\
Winzer & $1.36 \%$ & 0.40 & 0.46 \\
\hline
\end{tabular}

different approaches that will be shown in the following analyses.

To investigate the influence of PV systems on the short-term flicker, the correlation between the $P_{s t}$ and the grid voltage is a useful indicator. Relative grid 
voltages higher than $100 \%$ of the nominal grid voltage $\left(U_{N}\right)$ leads to a high power feed-in. It can, therefore, be assumed that the corresponding flickers can be caused by PV systems and loads during days with a fluctuating cloudiness or only by loads on clear sky days. Voltages lower than $100 \% U_{N}$ occur during times with lower or even no PV power feed in, and therefore, without any noticeable irradiation changes. Thus, flickers that appear on these lower voltages can be attributed to loads.

Fig. 2 visualizes the short-term flicker depending on the relative grid voltage. High densities of flicker values are red, low densities are blue. Most of the short-term flickers are within a range below 0.15 and occur at voltages between $98 \%$ and $101 \%$ of the nominal grid voltage. Many of the high short-term flicker values of 0.15 up to 0.6 are detected at voltages higher than $100 \% U_{N}$. These flicker values can be attributed to the power feedback situation. Most of the installed PV systems are connected to phase one of the electricity grid [9]. Due to that, differences between the phases are expected. There is in fact a slight disparity but it is still marginal. In general, there is a considerable scatter of the $P_{s t}$ values on each phase. Therefore, only one phase is shown in most of the following evaluations.

\subsection{Correlation of the Short-Term Flicker with the Time of the Day}

In this part of the investigation, the short-term flicker is assigned to the time of the day. Therefore all day courses of the $P_{s t}$ values are superimposed. Fig. 3 shows the result for phase one of the exemplary LV grid.

Fig. 3 displays the short-term flicker in the range from zero to one. In the night hours, the level is low, at around 0.1. During daytime, a bigger spread at a higher level occurs. Therefore, the density of these levels is lower.

There is a slight peak at noon. This peak could be caused by PV systems. It is obvious that during

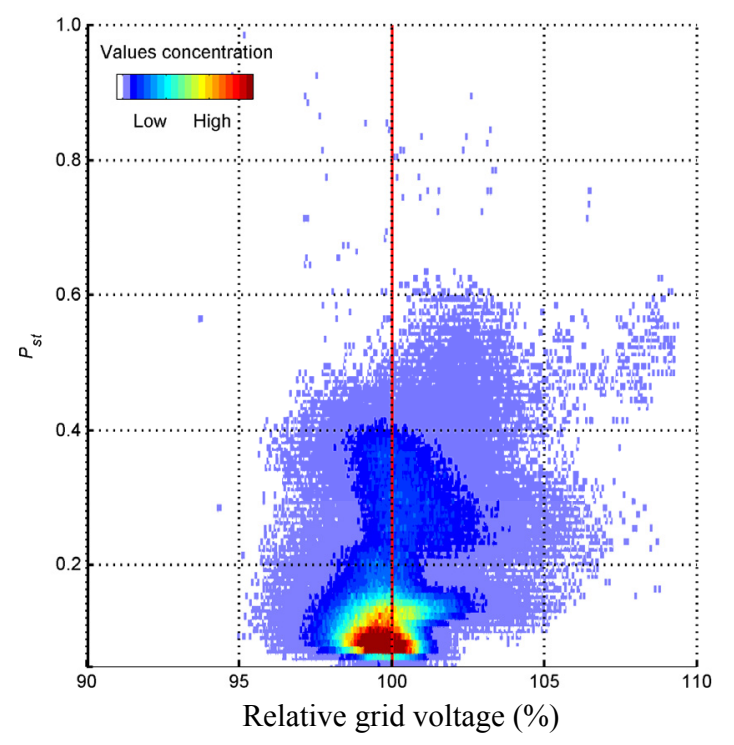

Fig. 2 Visualization of the short-term flicker in dependency of the relative grid voltage. Higher flicker values occur mainly at voltages higher than $100 \% U_{N}$.

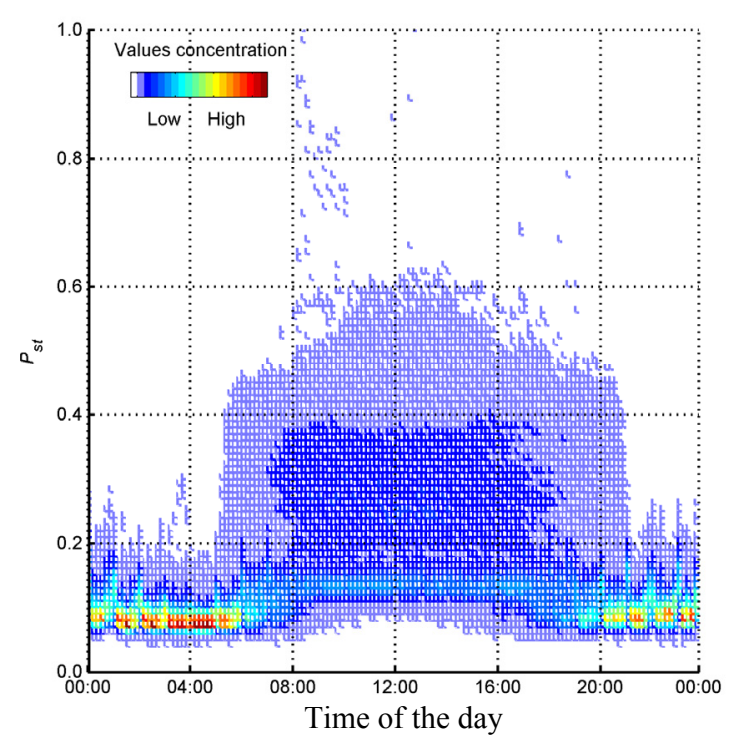

Fig. 3 Visualization of the short-term flicker over the time of the day. Higher flicker levels can be seen during daytime with a slight peak at noon.

daytime, the flicker level is higher due to the living habits of people. The connected loads, such as motors, consumer electronics or agricultural and industrial machines, consume higher loads, and therefore, have a higher impact on voltage fluctuations and on the flicker. During night, much less machines or other devices are in use. 


\subsection{Correlation of the Short-Term Flicker with the Date of the Year}

After the correlation with the time of the day, the day of the year correlation is the logical next step. PV systems produce a large part of their yearly electricity in the months May, June, July and August. If PV systems have a noticeable impact on the flicker level, the expected level in these time period should be higher than that during the rest of the year.

Fig. 4 shows the short-term flicker on phase one for the whole year 2012. There are some data gaps, especially in June. The flicker level remains nearly constant over the complete year. Only a flimsy enhancement in June and July is visible. There is no obvious drop in the winter months. This leads to the conclusion that the flicker level caused by loads is at least as high as the level caused by PV systems. Even the few high levels in the summer months could be evoked by loads.

Fig. 5 shows the behavior of the daily flickers throughout the year. The duration of higher flicker levels during the days is a function of the day of the year. Long summer days are an indicator for longer high flicker levels. This fits with the rhythm of the human routine as well as with the PV production.

\subsection{Correlation of the Short-Term Flicker with the Global Irradiation}

To investigate the influence of PV systems on the flicker, it is essential to calculate the correlation to the global irradiation. In this paper, that is done in two different ways:

- 10-min average values of the irradiation $\left(G_{\text {mean }}\right)$;

- difference between maximum and minimum irradiation in a 10-min interval $\left(G_{\text {diff }}\right)$.

The short-term flicker refers to a 10-min time slot. In comparison to that, the global irradiation is available as a high precision one second value for ten different locations in the investigation area. To correlate the time series, it is obvious to calculate 10-min average irradiation values with the knowledge that all enhanced

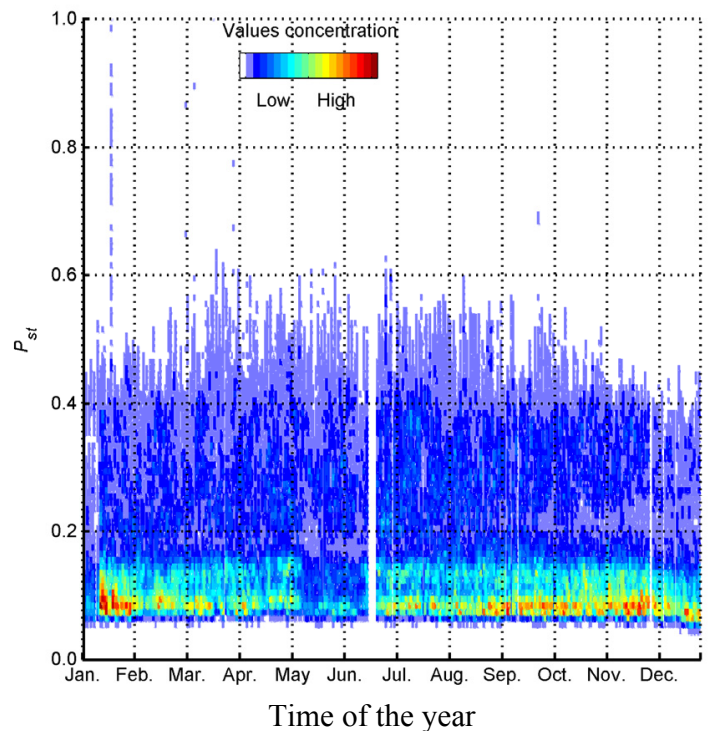

Fig. 4 Visualization of the short-term flicker in dependency of the day of the year. Marginally higher flicker levels can be seen in June and July with a slight peak at the end of June.

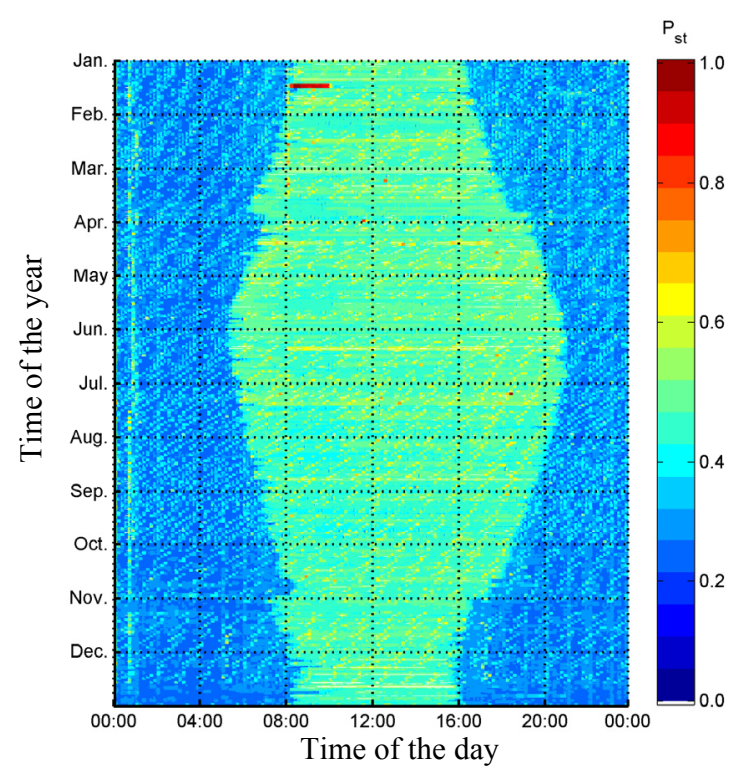

Fig. 5 Visualization of the short-term flicker in dependency of the time of the day and the day of the year. The length of higher flicker levels during daytime varies during the year.

irradiation values are smoothed. The results of this examination refer to the time period (June 1, 2012 to October 10,2012) because of the data availability. In this period, ten autarkic sensors located distributed in the investigation area deliver irradiation and ambient temperature on the horizontal plane. For each low 
voltage grid, the irradiation of the nearest sensor is used.

Fig. 6 outlines the result. Each flicker level correlates to one ten-min average irradiation value. A small increase to higher flicker levels on high irradiation values can be seen. The $90 \%$ and $99 \%$ quantiles make the coherences more apparent. The flicker level is nearly independent on the irradiation. Even at cloudy days with maximum irradiations around $300 \mathrm{~W} / \mathrm{m}^{2}$, the flickers reach the same level as on days with a bright sunshine.

To separate the clear sky conditions from the fluctuating cloudiness with a possible impact on the flicker level, the "maximum difference" per 10-min raster is calculated. This "maximum difference" is the difference between the absolute maximal to the absolute minimal irradiation in a 10-min interval. On a clear sky day, this value is low. On days with a highly volatile irradiation profile, the "maximum difference" can reach values up to $1,000 \mathrm{~W} / \mathrm{m}^{2}$.

The results are displayed in Fig. 7. It is expected to receive excessive flicker levels at higher "maximum difference" irradiations. The $90 \%$ and $99 \%$ quantiles makes the constant flicker level scattering evident.

To sum up these two different approaches: slightly higher flicker levels occur on higher mean irradiation values, but not on higher "maximum difference" irradiations. This leads to the suggestion that higher flicker levels are produced by loads during daytime. This is consistent with the evaluation of the flicker in dependency of the time of the day and the typical human behavior.

To eliminate the influence of the loads as effective as possible, the same evaluation as shown in Fig. 7 is done only for Sundays. Assuming that most of the loads are shut down on the weekend, especially on Sundays, the effect of PV systems should be more apparent.

The flicker values on Sundays in dependency of the "maximum difference" irradiation are revealed in Fig. 8. Again the distribution remains nearly constant.

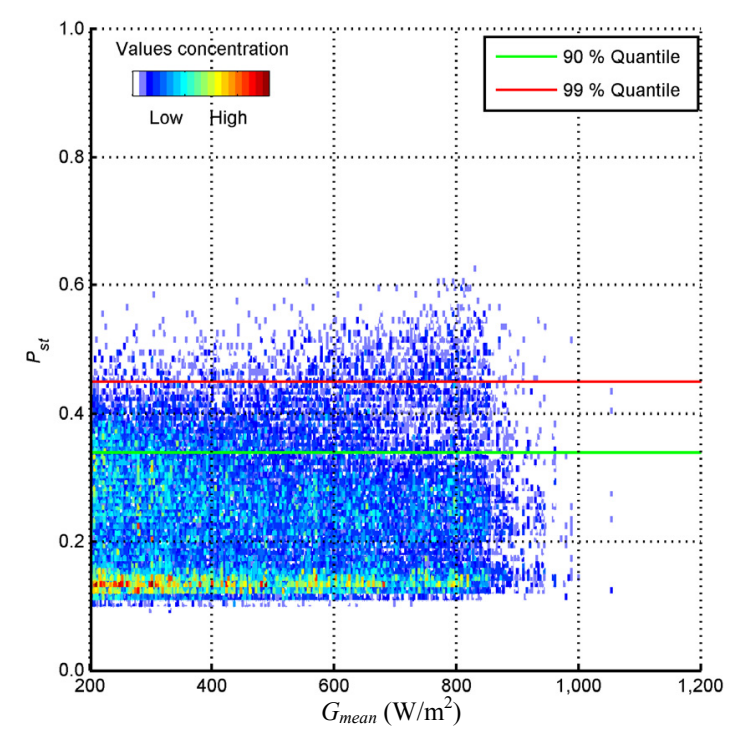

Fig. 6 Visualization of the short-term flicker in dependency of the 10-min average irradiation value. Considerably higher flicker levels can be seen with increasing irradiances.

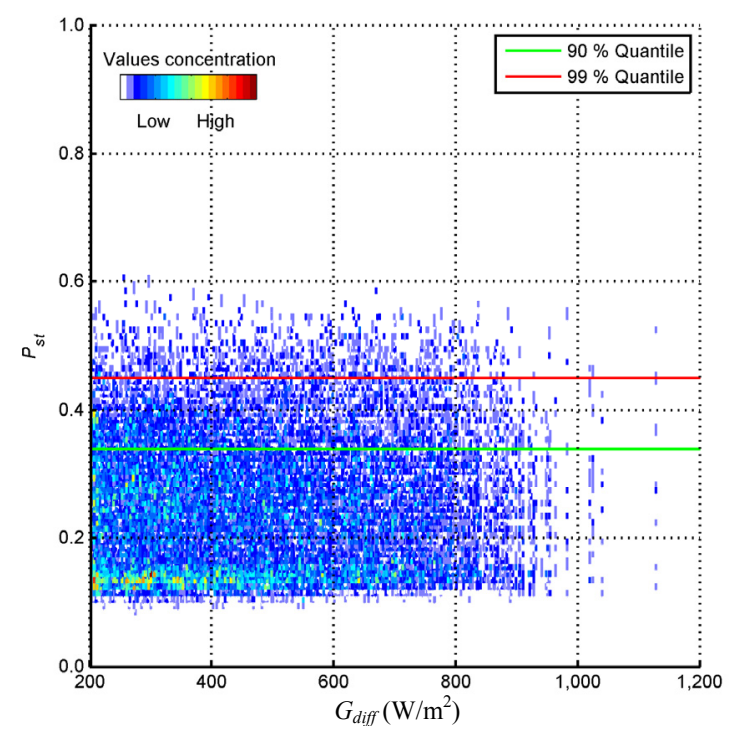

Fig. 7 Visualization of the short-term flicker in dependency of the ten minutes "maximum difference" irradiation value. The flicker level remains constant.

Nevertheless, to exclude the influence of a fluctuating cloudiness on the maximum flicker level, the evaluation of the correlation with the clear sky index is done in the following section.

\subsection{Correlation of the Short-Term Flicker with the Clear Sky Index}

Days with a fluctuating cloudiness exhibit clear sky 


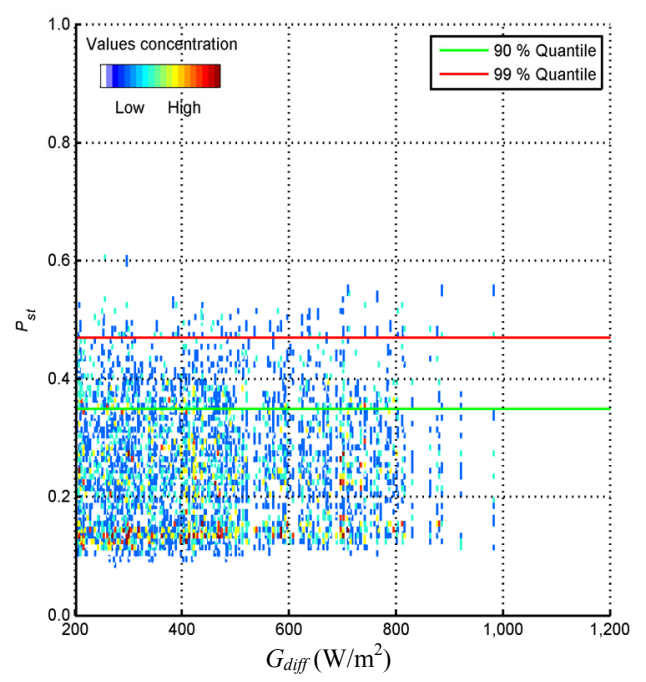

Fig. 8 Visualization of the short-term flicker in dependency of the 10-min "maximum difference" irradiation value on Sundays. The flicker level still remains constant.

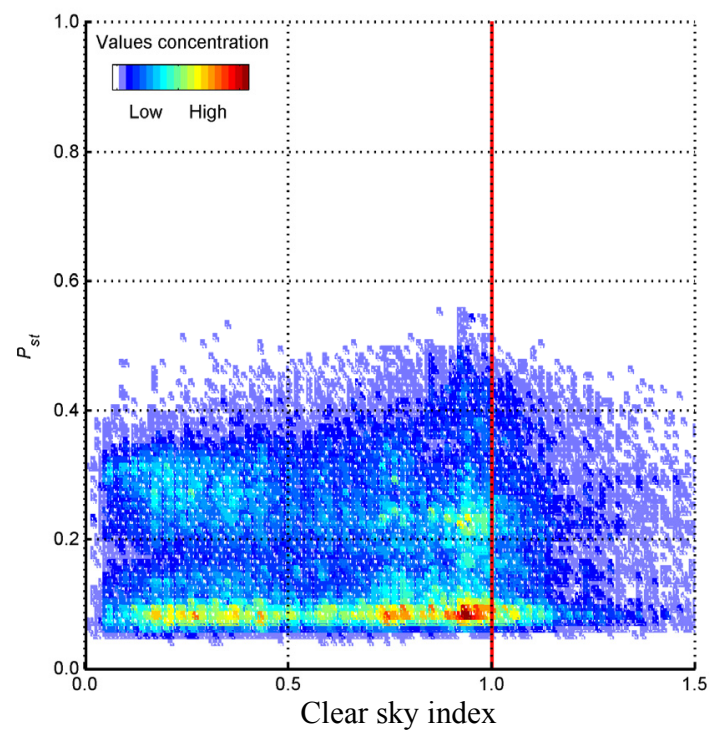

Fig. 9 Visualization of the short-term flicker in dependency of the clear sky index for phases one. Despite obvious differences in the phases, all three do not show elevated flicker values at clear sky index values unlike one.

index values unequal to one. The values can be lower due to cloud shadowing or higher due to irradiation enhancements [8]. Consequently, influences of PV systems on the flicker value should occur on clear sky index values unequal to one.

Fig. 9 illustrates the flicker value in dependency of the clear sky index. Despite differences in the phases, all of them do not show elevated flicker values at clear sky indexes unequal to one.

Fig. 9 displays the highest flicker values at a clear sky index around one on phase one. This can again be attributed to the ordinary human behavior and due to that contributed to loads. Furthermore, the investigated low voltage grid is a rural area with a high density of agricultural loads. These loads are mainly used outside on sunny days.

A similar behavior at least in the density of the flicker level shows phase two. On phase three, the distribution of the flicker level is nearly constant. The most serious difference between phase three and phases one and two is the absolute level of the flicker. Phase three has a maximum level around 0.3, phases one and two of 0.4 up to 0.6. Due to that conspicuousness, there are more and/or stronger loads connected to phases one and two than to phase three.

Once again, no influence of PV systems on the maximum flicker level can be obtained.

\subsection{Comparison of the Flicker Level on a Long Feeder with PV System on a Clear Sky Day with a Fluctuating Day}

A nearly entire elimination of the load is possible by considering only one long feeder with a huge PV system on Sundays. This evaluation is done in this part of the evaluation.

In this approach, the irradiation profiles of all Sundays are analysed. The most fluctuating and clear sky irradiation profiles are taken into account. The measured house connection is at the end of a long feeder and a $16.7 \mathrm{~kW}$ PV system is installed.

Figs. 10 and 11 show the irradiation and flicker profiles for these two exemplary days on the chosen grid node. Blue represents the irradiation in $\mathrm{W} / \mathrm{m}^{2}$, red the flicker level $P_{s t}$. The evoked flickers are in the same range on both days. There are high peak flicker values at times with no or very low irradiance. These values can again be attributed to the influence of loads. It should always be taken into account that the measured values are far below the normative limit of one. The peak values of this evaluation are below 0.2 . 


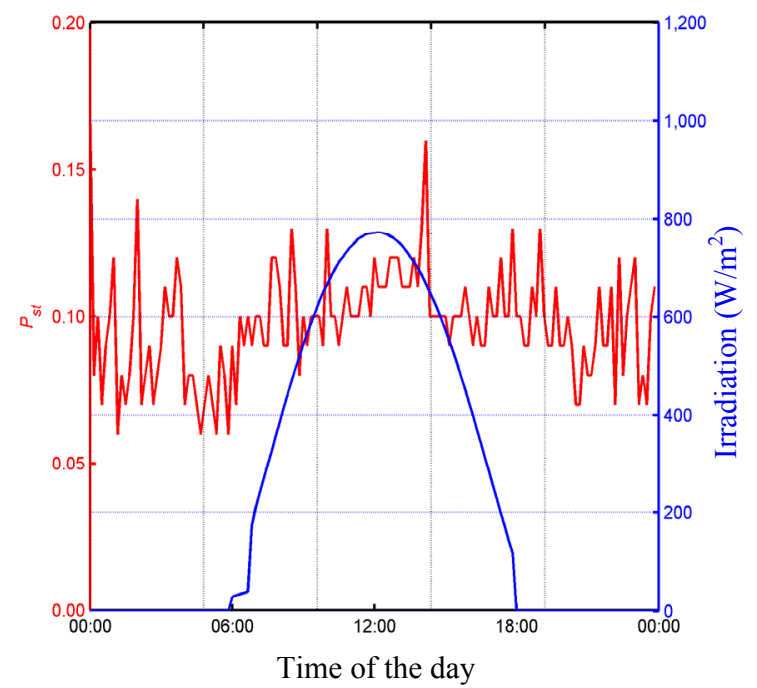

Fig. 10 Visualization of the short-term flicker (red) and the irradiation (blue) at the end of a long feeder for a clear sky day.

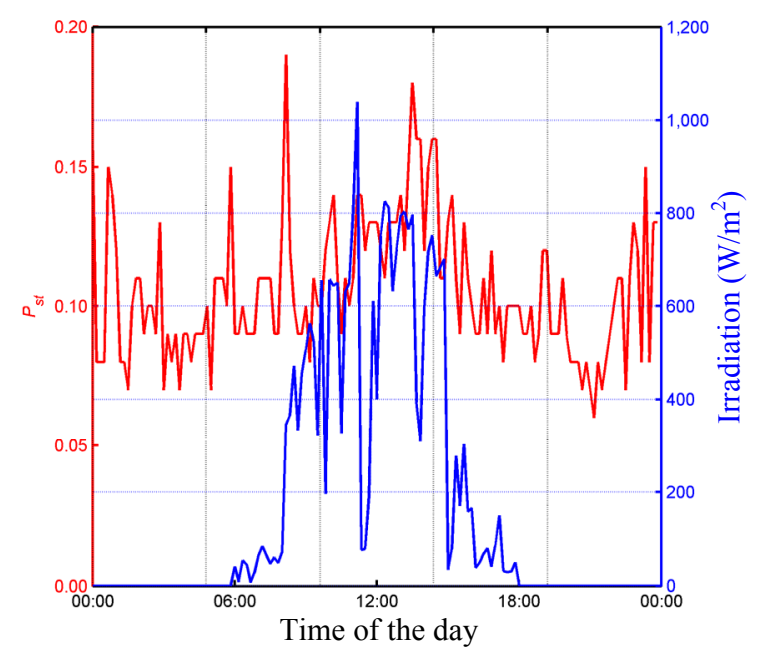

Fig. 11 Visualization of the short-term flicker (red) and the irradiation (blue) at the end of a long feeder for a fluctuating day.

3.8 Investigation of the Flicker Level on Cloudy Days with Almost No PV Feed-in and on Clear Sky Days with No Impact of PV Systems on the Flicker Level

The goal of this section, in contrast to the last analysis, is to eliminate the influence of PV systems on the flicker level. Therefore, days with a thick cloud cover and clear sky days without any feed-in fluctuations are examined.

In the first part, only the cloudiest days in 2012 are analysed. The choice of the days was done by a FFT (Fast Fourier Transformation) and filtering algorithm [10]. This algorithm sorts the daily irradiation profiles in twelve categories in dependency of the irradiation gradients and the maximum irradiations. All analysed days do not reach irradiation values higher than 350 $\mathrm{W} / \mathrm{m}^{2}$. Fig. 12 displays the daily irradiation profiles of the four cloudiest days in 2012.

The inherent flicker values of these four cloudy days are displayed in Fig. 13. The comparison of Fig. 13 with Fig. 3 shows a slightly reduced maximum flicker level. There are higher flicker values during day time because of the human daily life. The maximum $P_{s t}$ value was measured on January 18, 2012. On this day, the short-term flickers on phase one of the electricity grid reached a maximum value of 1.38 , on phase two of 1.31 and on phase three of 1.17. This day was a sunny Wednesday without any irradiance fluctuations. Due to this awareness of the flicker, Fig. 14 displays the daily irradiation profiles of eight days in 2012 with no fluctuations in the irradiation. All these days are almost perfect clear sky days. The maximum irradiation depends on the day of the year.

The inherent flicker values of these eight clear sky days are displayed in Fig. 15. The comparison of Fig.

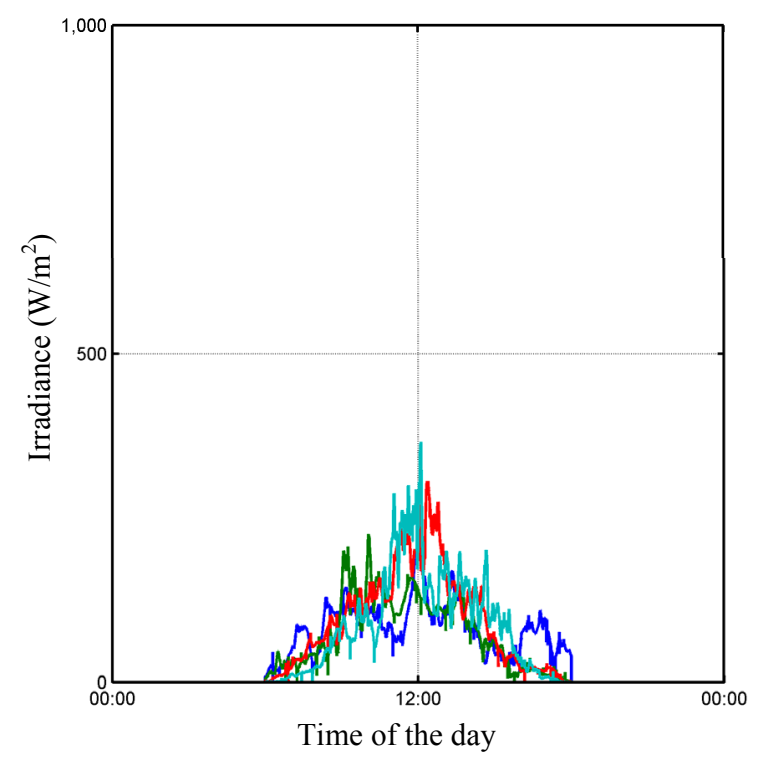

Fig. 12 Daily irradiation profiles of four days in 2012 with a thick cloud cover. 


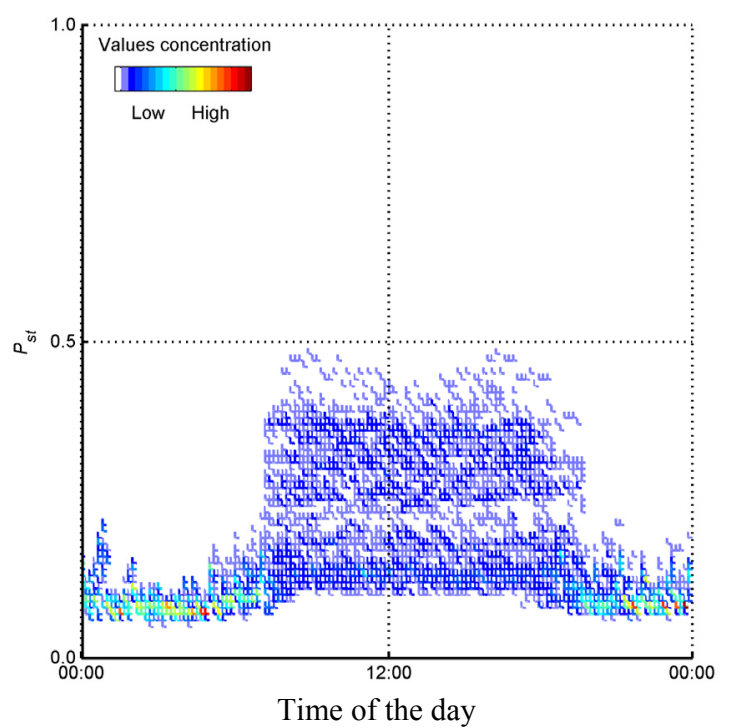

Fig. 13 Visualization of the short-term flicker in dependency on the time of the day on days with a thick cloud cover. Again higher flicker levels can be seen during daytime.

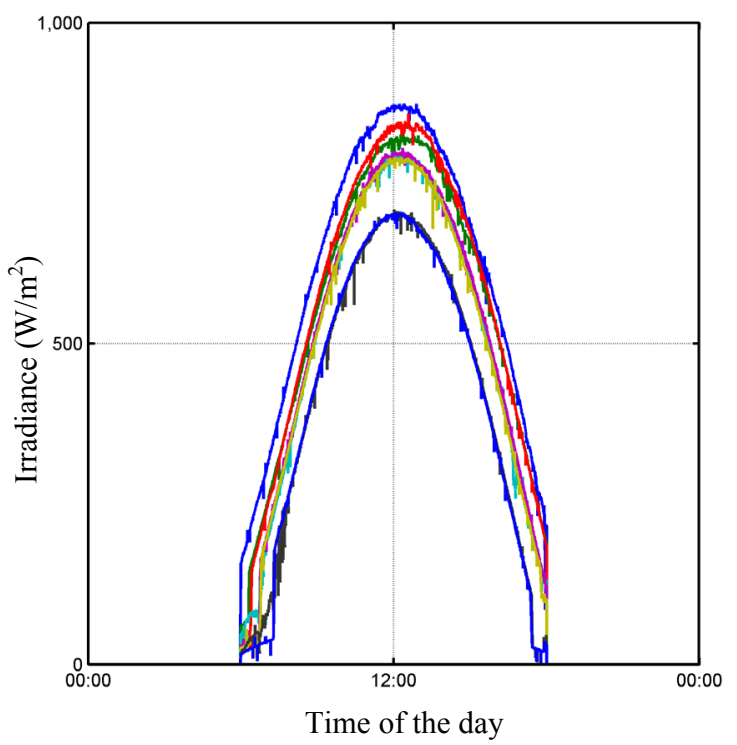

Fig. 14 Daily irradiation profiles of eight days in 2012 without any irradiance fluctuations.

15 with Fig. 3 shows no differences in the maximum flicker level. There are higher flicker values during day time because of the human daily life. All flickers on these days have to be generated by loads.

To compare these load-occasioned flicker with the flicker on days with a strong fluctuating cloudiness the days with the highest gradients of the irradiance are taken into account. Fig. 16 shows the day course of the

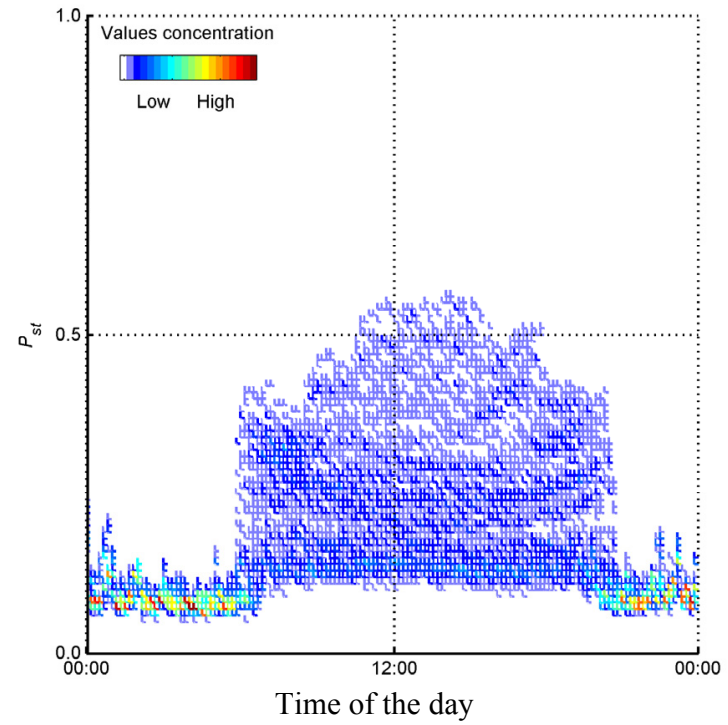

Fig. 15 Visualization of the short-term flicker in dependency on the time of the day on days without any irradiance fluctuations. Again higher flicker levels can be seen during daytime.

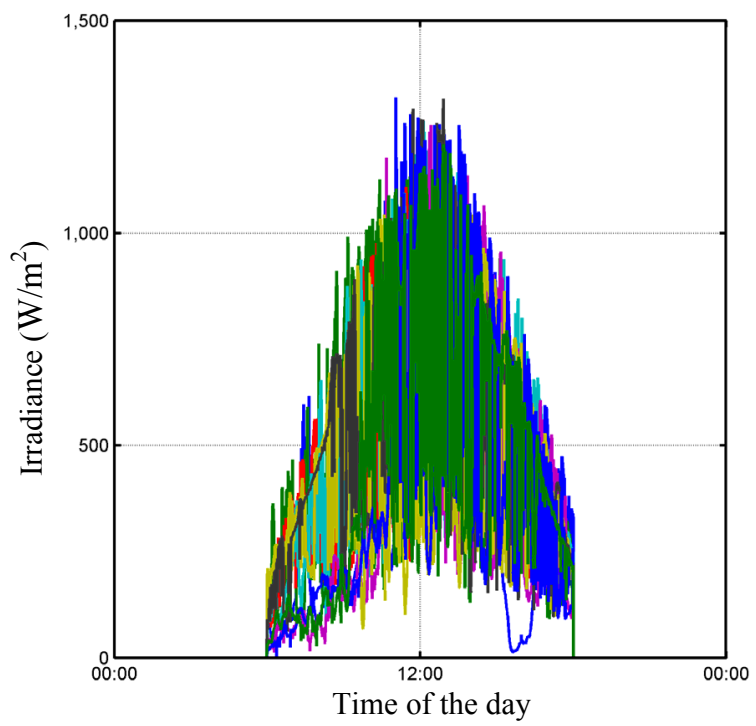

Fig. 16 Daily irradiation profiles of eight days in2012 with strong irradiance fluctuations.

irradiance. The correlated flicker is depicted in Fig. 17. The maximum flickers are slightly reduced compared to the maximum flickers on clear sky days. Consequently, the highest flicker values are not evoked by PV systems.

\section{Summary and Conclusion}

In this paper, the influence of PV systems on the 


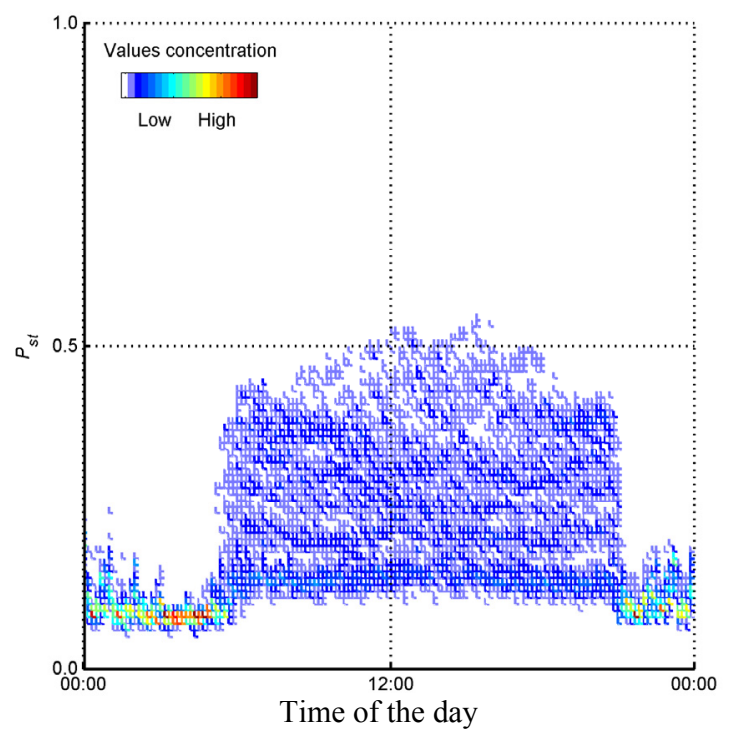

Fig. 17 Visualization of the short-term flicker in dependency on the time of the day on days with strong irradiance fluctuations.

flicker level in an area with a high PV penetration is analysed. Therefore, measurement data from around 560 smart meters for two years are available. The survey is done for various low voltage grids with different supply structures.

The evaluation delivered the following results: the permissible value for power quality of the long-term flicker $\left(P_{l t} \leq 0.5\right)$ [4] is not always respected. Nevertheless, these values are very rare.

Different approaches to determine the effects of the PV feed-in on the flicker level and to isolate the effects of the load on the flicker level were taken into account. The evaluation of the $P_{s t}$ in dependency on the relative grid voltage shows slightly above average flicker values at voltages higher than $100 \%$ of the nominal grid voltage. These values can be caused not only by PV systems on days with a fluctuating cloudiness, but also by loads at clear sky days with a high PV feed-in. The investigation of the $P_{s t}$ in dependency on the time of the day and the day of the year leads to no knowledge of the influence of PV systems. By calculating the correlation between flicker value and global irradiation or clear sky index, no influence is obvious. The loads do have a more significant influence on the flicker. The evaluation of the flicker level on days with a thick cloud cover and on clear sky days shows as high flicker levels as days with a fluctuating cloudiness. These values can be completely attributed to loads.

In conclusion, it can be stated that no higher flicker levels are caused by PV systems. The determining factor still remains the load. This statement is only applicable under the current planning conditions. If these conditions change, for example, the maximum voltage hub in low voltage grids of 3\% [4], these statements lose their validity. If the PV penetration reaches higher values in the future, this study has to be implemented again to investigate the influence of these new high penetrations on the flicker level. Nevertheless, there are no high deviations in the flicker level expected.

\section{Acknowledgements}

The authors thank the Bayernwerk AG (formerly E.ON Bayern AG) for providing measurement data and financial support, in particular, the Asset Management Department for their invaluable technical assistance. Likewise, we thank Sebastian Schmidt and Johannes Brantl for profitable discussions.

\section{References}

[1] Spring, A., Wirth, G., Becker, G., Pardatscher, R., Witzmann, R., Brantl, J., and Schmidt, S. 2013. "Untersuchung der Korrelation aus Tageslastgängen und PV Einspeisung zur Bestimmung der maximalen Netzbelastung." Presented at the 28th Symposium Photovoltaische Solarenergie, Kloster Banz, Germany.

[2] VDE0847-4-15EMC (Electromagnetic Compatibility). 2010. IEC 61000-4-15: Testing and Measurement Techniques-Flickermeter. Functional and Design Specifications. IEC standards report.

[3] Schlabbach, J., and Cichowski, R. 2013. Netzanschluss von EEG-Anlagen, 5th ed. Berlin: VDE Verlag.

[4] VDE-AR-N 4105: Application Guideline. 2011. Erzeugungsanlagen am Niederspannungsnetz. Technische Mindestanforderungen für Anschluss und Parallelbetreib von Erzeugungsanlagen am Niederspannungsnetz. VDE Standard.

[5] Schlabbach, J., and Mombauer, W. 2008. Power 
Quality-Entstehung und Bewertung von Netzrückwirkungen; Netzanschluss erneuerbarer Energiequellen. Berlin, Offenbach: VDE Verlag.

[6] Wirth, G., Spring, A., Becker, G., Pardatscher, R., Witzmann, R., Brantl, J., and Garhamer, M. 2012. "Effects of a High PV Penetration on the Distribution Grid." Presented at the 27th European Photovoltaic Solar Energy Conference, Frankfurt, Germany.

[7] E.ON Bayern AG. 2012. "Grid of the Future." Research Project. Accessed December 3, 2014. https://www.bayernwerk.de/cps/rde/xchg/bayernwerk/hs.1 /280.htm.

[8] Zehner, M., Moll, M., Thaler, S., Schrank, O., Hartmann, M., Mayer, B., Betts, T., Gottschalg, R., Behrens, K., Riecke, W., Knaupp, W., Giesler, B., Becker, G., and Mayer, O. 2012. "Quantifizierung von
Einstrahlungsüberhöhungen in hoch aufgelösten DWD-Datensätzen für verschiedene Standorte in Deutschland." Presented at the 27th Symposium Photovoltaische Solarenergie, Kloster Banz, Germany.

[9] Pardatscher, R., Witzmann, R., Wirth, G., Spring, A., Becker, G., Brantl, J., and Schmidt, S. 2012. "Analyse von Lastgangzählerdaten aus dem Projekt 'Netz der Zukunft'." In Proceedings of VDE Kongress 2012, 1-6.

[10] Rauscher, T., Thaler, S., Hinterberger, L., Zehner, M., Hartmann, M., Becker, G., Mayer, B., Giesler, B., Mayer, O., Betts, T., and Gottschalg, R. 2013. "Strahlungscharakterisierung Meteorologischer Tagesgänge und Einstrahlungsüberhöhungen zur Optimierung von PV-Systemen." Presented at the 28th Symposium Photovoltaische Solarenergie, Kloster Banz, Germany. 